\title{
OPEN Author Correction: Insights into Pasteurellaceae carriage dynamics in the nasal passages of healthy beef calves
}

\author{
A. C. Thomas (D), M. Bailey, M. R. F. Lee, A. Mead, B. Morales-Aza, R. Reynolds (D), B. Vipond, \\ A. Finn \& M. C. Eisler \\ Correction to: Scientific Reports https://doi.org/10.1038/s41598-019-48007-5, published online 16 August 2019
}

The Acknowledgements section in this Article is incomplete.

"The authors thank Rothamsted Research (BBS/E/C/000J0100) for hosting animal work; Hannah Fleming, Bruce Griffith and Simon White for excellent support and animal care during sample collection periods (Rothamsted Research); the late Robert Orr for initial contributions towards study conceptualisation and extensive knowledge of the North Wyke Farm Platform operations (Rothamsted Research); Debbie Langton for sequencing support (University of Bristol). The authors acknowledge the support from the NIHR Health Protection Research Unit in Evaluation of Interventions at University of Bristol.”

should read:

"This work was funded by the Biotechnology and Biological Sciences Research Council (BBSRC) under an Industrial Case Studentship (BB/J012483/1). The authors thank Rothamsted Research (BBS/E/C/000J0100) for hosting animal work; Hannah Fleming, Bruce Griffith and Simon White for excellent support and animal care during sample collection periods (Rothamsted Research); the late Robert Orr for initial contributions towards study conceptualisation and extensive knowledge of the North Wyke Farm Platform operations (Rothamsted Research); Debbie Langton for sequencing support (University of Bristol). The authors acknowledge the support from the NIHR Health Protection Research Unit in Evaluation of Interventions at University of Bristol."

In addition, this Article contains ambiguous wording in the Results section, under subheading 'Duration of carriage and hazard of clearance'. To clarify the findings, the following text should be disregarded:

"these trends were non-linear with categories 2 and 4 associated with a longer duration (lower hazard) compared to category 3 , and category 4 (highest density) associated with the longest subsequent carriage duration (Table 3)."

(i) Open Access This article is licensed under a Creative Commons Attribution 4.0 International License, which permits use, sharing, adaptation, distribution and reproduction in any medium or format, as long as you give appropriate credit to the original author(s) and the source, provide a link to the Creative Commons license, and indicate if changes were made. The images or other third party material in this article are included in the article's Creative Commons license, unless indicated otherwise in a credit line to the material. If material is not included in the article's Creative Commons license and your intended use is not permitted by statutory regulation or exceeds the permitted use, you will need to obtain permission directly from the copyright holder. To view a copy of this license, visit http://creativecommons.org/licenses/by/4.0/.

(C) The Author(s) 2019 